DOI: 10.12731/2658-6649-2020-12-1-71-78

УДК 574.24

\title{
АНАЛИЗ КОРРЕЛЯЦИОННОЙ ЗАВИСИМОСТИ РЕЗУЛЬТАТОВ ТОКСИКОЛОГИЧЕСКИХ ЭКСПЕРИМЕНТОВ ОТ УРОВНЯ рН ВОДЫ
}

\author{
Александрова В.В., Иванов В.Б., Войтова В.А.
}

В основу исследования положены экотоксикологические эксперименmыl, с использованием тест-объекта Ceriodaphnia affinis. Исследовалось влияние количества химических веществ на тест-обьект Ceriodaphnia affinis, а так же проводился анализ зависимости результатов токсикологических экспериментов от уровня рН воды.

Цель исследования заключается в исследование влияния количества химических веществ на тест-обьект Ceriodaphnia affinis, а так же анализ зависимости результатов токсикологических экспериментов от уровня $\mathrm{pH}$ воды.

Материалы и методы исследования. В течении двух лет с 2018 по 2019 год проводилось токсикологическое исследование проб воды реки Обь в 10 точках отбора проб (точки 1-10), параллельно проводился химический анализ проб воды и определение уровня $\mathrm{pH}$.

Заключение. Экологическое состояние исследованных рек Нижневартовского района на основании полученных химических и токсикологических анализов позволяет говорит о их удовлетворительном состоянии, реки преимущественно загрязнены железом и марганцем, поверхностные воды Нижневартовского района преимущественно кислье, что во многом объясняется природным происхождением. Коррелячионную зависимость плодовитости тест-объектов с уровнем рН воды рек Обь в районе города Нижневартовска можно охарактеризовать как низкую.

Ключевые слова: тест-объект; Ceriodaphnia affinis; метод биотестирования; рН воды; химические вещества.

\section{ANALYSIS OF THE CORRELATION BETWEEN THE RESULTS OF TOXICOLOGICAL EXPERIMENTS AND THE pH LEVEL OF WATER Aleksandrova V.V., Ivanov V.B., Vojtova V.A.}

The research is based on ecotoxicological experiments using the test object Ceriodaphnia Affinis. We studied influence of various amounts of chemical 
substances on the Ceriodaphnia affinis was studied and analyzed dependence of toxicological experiments results on the water $\mathrm{pH}$ level.

The goal of the research is to study the effect of various amounts of chemicals on the Ceriodaphnia affinis, as well as to analyze the dependence of the results of toxicological experiments on the $\mathrm{pH}$ level of water.

Research Materials \& Methods. During two years, i.e. from 2018 to 2019, the toxicological testing of water samples from the Ob river was carried out at 10 sampling points (points 1-10), at the same time a chemical analysis of water samples and determination of the $\mathrm{pH}$ level was performed.

Conclusion. The ecological condition of the studied rivers of the Nizhnevartovskiy district on the basis of the received chemical and toxicological analyses allows to draw a conclusion about their satisfactory condition, the rivers are mainly polluted with iron and manganese, the surface waters of the Nizhnevartovskiy district are mainly acidic, which is largely explained by their natural origin. The correlation dependence of the test objects fertility on the water $\mathrm{pH}$ level in the Ob river close to the City of Nizhnevartovsk can be characterized as low.

Keywords: test object; Ceriodaphnia affinis; bioassay method; $p H$ of water; chemicals.

\section{Введение}

Исследование воздействия нефтегазодобывающей промышленности на окружающую среду на основе изучения состояния поверхностных вод и донных отложений в зоне воздействия имеет большую актуальность [5, $6,10,11,13]$.

Оценка качества природных и сточных вод в настоящее время проводиться по результатам химических анализов проб воды, а так же по результатам биотестирования проб воды в лабораторных условиях. И тот, и другой метод имеет ряд недостатков. Недостатками оценки качества природных и сточных вод по результатам химического анализа является то, что для разных регионов характерна фоновая концентрация разных химических веществ, природные объекты регионов характеризуются своими особенностями, к примеру, воды рек Нижневартовского района преимущественно кислые $[7,8,9,13]$.

Цель исследования заключается в исследование влияния количества химических веществ на тест-обьект Ceriodaphnia affinis, а так же анализ зависимости результатов токсикологических экспериментов от уровня $\mathrm{pH}$ воды. 


\section{Материалы и методы исследования}

В течении двух лет с 2018 по 2019 год проводилось токсикологическое исследование проб воды реки Обь в 10 точках отбора проб (точки 1-10), параллельно проводился химический анализ проб воды и определение уровня $\mathrm{pH}$.

\section{Результаты исследования и их обсуждение}

Биотестирование, как интегральный метод оценки токсичности водной среды, является дополнением к химическому анализу, однако интерпретация результатов биотестирования, как по показателю выживаемости, так и по показателю плодовитости сложна $[1,3,4]$. Анализ влияния $\mathrm{pH}$ воды на плодовитость тест-объекта Ceriodaphnia affinis проводили с помощью корреляционного анализа $[2,3]$.

Четкой закономерности спада и повышения плодовитости лабораторной культуры цереодафний в период исследования в 2018 г. и 2019 г. не отмечено, показатели каждого года отличаются своими особенностями. На рис. 1 мы наблюдаем первый пик подъема плодовитости в 2018 году в точке №1, где количество химических веществ достигло максимальных значений, затем в точках №2-8 последовал планомерный спад веществ, достигнув минимума в точке №10. Наиболее значительный уровень плодовитости тест-объектов зафиксированы в точках №3-5, где в точке №4 было произведено наибольшее количество молоди, при том, что уровень химических веществ планомерно снижался до минимальных значений.

В точке №9 мы наблюдаем равное отношение химических веществ на среднее количество молоди. 2019 год характеризуется практически схожими значениями суммарного количества химических веществ со значениями 2018 года, где максимальный пик зафиксирован в точке №4, при этом показатели количества молоди тест-объектов относительно стабильны. Следовательно, колебания плодовитости у тест-объектов могут быть обусловлены не только токсическим воздействием химических веществ, но и генетическими и внутрипопуляционными факторами.

Пробы воды реки Обь содержали такие вещества как: железа (растворенная форма), ионы аммония, марганец (растворенная форма), нефтепродукты, хлорид-ионы. В токсикологических экспериментах исследовали суммарное содержание всех найденных, при химическом анализе воды, минеральных веществ. 


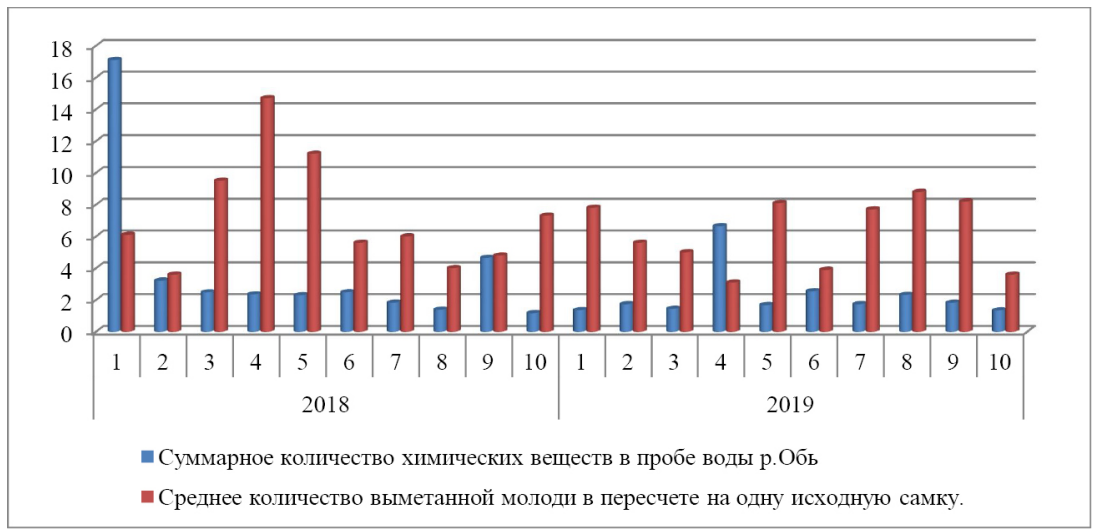

Рис. 1. Влияние суммарного количества химических веществ на среднее количество выметанной молоди в пересчет на одну исходную самку в пробах воды реки Обь (точки исследования 1-10)

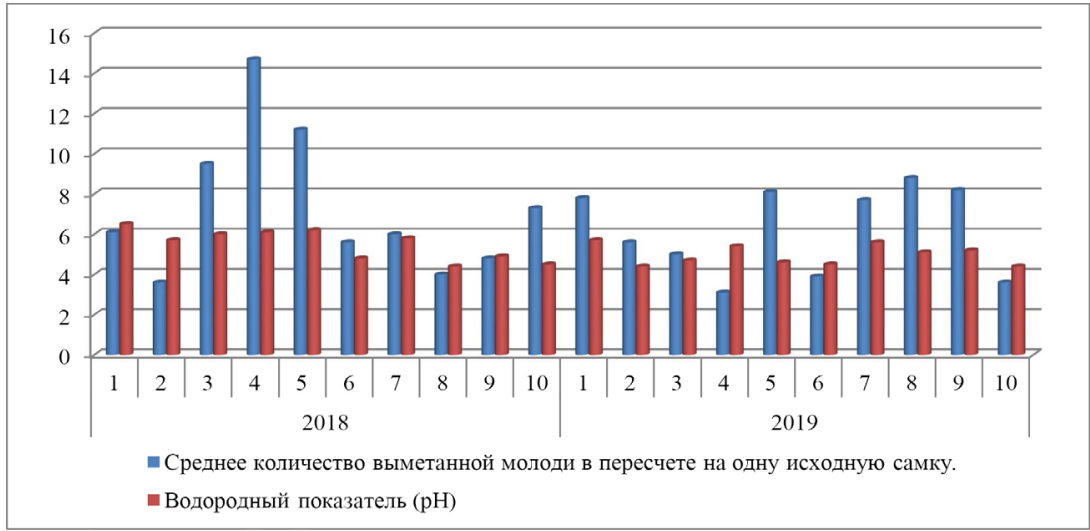

Рис. 2. Влияние уровня водородного показателя (pH) на среднее количество выметанной молоди в пересчете на одну исходную самку в пробах воды р.Обь (точки исследования 1-10)

Учитывая то, что воды рек Нижневартовского района преимущественно кислые, мы также выявили закономерность влияния уровня $\mathrm{pH}$ на среднее количество выметанной молоди тест-объектов. На рис. 2 показана динамика значений водородного показателя в 2018 и 2019 году, в 2018 году показатель $\mathrm{pH}$ от 6,5 до 4.4 ед., что дает положительную реакцию на количество выметанной молоди (в точках №3-5). Относительно схожие 
значения зафиксированы и в 2019 году, где также в пробах воды отмечен низкий уровень $\mathrm{pH}$, минимальные значения которого замечены лишь в $30 \%$ случаях (в точках №4,6 и 10), здесь показатель $\mathrm{pH}=5,4$ и 4,4 ед.

Корреляционная зависимость токсичности по критериям плодовитости тест-объекта Ceriodaphnia affinis, с $\mathrm{pH}$ воды реки Обь составила $\mathrm{r}=0,42$, данную зависимость можно охарактеризовать как низкую.

\section{Заключение}

Экологическое состояние исследованных рек Нижневартовского района на основании полученных химических и токсикологических анализов позволяет говорит о их удовлетворительном состоянии, реки преимущественно загрязнены железом и марганцем, поверхностные воды Нижневартовского района преимущественно кислые, что во многом объясняется природным происхождением. Корреляционную зависимость плодовитости тест-объектов с уровнем рН воды рек Обь в районе города Нижневартовска можно охарактеризовать как низкую.

Работа выполнена при поддержке гранта РФФИ 18-44-860006.

\section{Список литературы}

1. Александрова В.В., Левкова А.Н., Логинов Д.Н., Иванов В.Б. Анализ и прогноз миграции антропогенных примесей в пробах донных отложений поверхностных вод Нижневартовского района // В мире научных открытий. 2017. № 9 (4-2). 180-186.

2. Александрова В.В. Применение метода биотестирования в анализе токсичности природных и сточных вод (на примере Нижневартовского района Тюменской области): Монография. Нижневартовск: Изд-во НГГУ, 2009. 92 с.

3. Александрова В.В. Анализ корреляционной зависимости выживаемости и плодовитости тест-объекта Ceriodaphnia affinis с химическим составом воды // Вестник Нижневартовского государственного университета. 2013. № 3. С. 60-63.

4. Александрова В.В. Определение качества природных вод методом биотестирования в полевых условиях // Известия Самарского научного центра Российской академии наук. 2013. Т. 15. № 3 (3). С. 897-899.

5. Александрова В.В., Левкова А.Н., Иванова А.В. Анализ и прогноз миграции химических веществ в поверхностных водах и донных отложениях малых рек // Siberian Journal of Life Sciences and Agriculture. 2019. T. 11. №2-2. C. 12-20. 
6. Александрова В.В., Иванов В.Б., Иванов Н.А., Марач В.С. Оценка качества воды озер Нижневартовского района по критерию выживаемости Daphnia magna // В мире научных открытий”. 2017. Т. 9. № 1-2. С. 36-41.

7. Александрова В.В. Биотестирование как современный метод оценки токсичности природных и сточных вод. Нижневартовск, 2013.

8. Александрова В.В., Иванов Н.А., Марач В.С., Иванов В.Б. Оценка токсичности вод озер Нижневартовского района // В мире научных открытий. 2017. T. 9. № 2-2. С. 53-57.

9. Александрова В.В., Логинов Д.Н., Войтова В.А. Корреляционный анализ миграции антропогенных примесей в донных отложениях методом химического анализа // В мире научных открытий. 2017. Т. 9. № 4-2. С. 186-191.

10. Волков И.М., Ряхин М.С., Белоусов С.Н., Александрова В.В., Иванов В.Б. Обеспечение экологической безопасности проектных решений на территории лицензионных участков недропользователей с применением наилучших доступных технологий // Нефтяное хозяйство. 2018. № 2. C. $109-112$.

11. Иванов В.Б., Долгих А.М., Логинов А.М., Иванова Л.Г. Проблема добычи углеводородов и рекультивации нефтезагрязненных земель на территории Ханты-Мансийского автономного округа-Югры // В мире научных открытий. 2018. Т. 10. № 3-2. С. 28-36.

12. Левкова А.Н., Иванов В.Б. Эколого-химический анализ состояния донных отложений малых рек Нижневартовского района в зоне воздействия нефтедобывающей промышленности // XIX Всероссийская студенческая научно-практическая конференция Нижневартовского государственного университета. Нижневартовск: Изд-во НВГУ, 2017. С. 355-360.

13. Усманов И.Ю., Иванов В.Б., Иванов Н.А. Самовосстановление экосистем Среднего Приобья при антропогенных воздействиях нефтедобывающего комплекса // Экологические проблемы бассейнов крупных рек - 6: Материалы международной конференции. Тольятти: Анна, 2018. С. 303-305.

\section{References}

1. Aleksandrova V.V., Levkova A.N., Loginov D.N., Ivanov V.B. V mire nauchnyh otkrytij. 2017. №9 (4-2), pp. 180-186.

2. Aleksandrova V.V. Primenenie metoda biotestirovaniya $v$ analize toksichnosti prirodnyh i stochnyh vod (na primere Nizhnevartovskogo rajona Tyumenskoj oblasti) [Application of the bioassay method in the analysis of toxicity of natural and waste waters (for example, Nizhnevartovsk district of the Tyumen region)]. Nizhnevartovsk: Izd-vo NGGU, 2009. 92 p. 
3. Aleksandrova V.V. Vestnik Nizhnevartovskogo gosudarstvennogo universiteta. 2013. № 3, pp. 60-63.

4. Aleksandrova V.V. Izvestiya Samarskogo nauchnogo centra Rossijskoj akademii nauk. 2013. V. 15. № 3 (3), pp. 897-899.

5. Aleksandrova V.V., Levkova A.N., Ivanova A.V. Siberian Journal of Life Sciences and Agriculture. 2019. V. 11. №2-2, pp. 12-20.

6. Aleksandrova V.V., Ivanov V.B., Ivanov N.A., Marach V.S. V mire nauchnyh otkrytij. 2017. V. 9. № 1-2, pp. 36-41.

7. Aleksandrova V.V. Biotestirovanie kak sovremennyj metod ocenki toksichnosti prirodnyh i stochnyh vod [Biotesting as a modern method for assessing the toxicity of natural and waste waters]. Nizhnevartovsk, 2013.

8. Aleksandrova V.V., Ivanov N.A., Marach V.S., Ivanov V.B. V mire nauchnyh otkrytij. 2017. V. 9. № 2-2, pp. 53-57.

9. Aleksandrova V.V., Loginov D.N., Vojtova V.A. Vmire nauchnyh otkrytij. 2017. V. 9. № 4-2, pp. 186-191.

10. Volkov I.M., Ryahin M.S., Belousov S.N., Aleksandrova V.V., Ivanov V.B. Neftyanoe hozyajstvo. 2018. № 2, pp. 109-112.

11. Ivanov V.B., Dolgikh A.M., Loginov A.M., Ivanova L.G. V mire nauchnyh otkrytij. 2018. V. 10. № 3-2, pp. 28-36.

12. Levkova A.N., Ivanov V.B. XIX Vserossiyskaya studencheskaya nauchno-prakticheskaya konferentsiya Nizhnevartovskogo gosudarstvennogo universiteta [XIX All-Russian Scientific and Practical Conference of the Nizhnevartovsk State University]. Nizhnevartovsk: Izd-vo NVGU, 2017, pp. 355-360.

13. Usmanov I.Yu., Ivanov V.B., Ivanov N.A. Ekologicheskie problemy basseynov krupnykh rek-6: Materialy mezhdunarodnoy konferentsii [Ecological problems of large river basins - 6: Materials of an international conference]. Tol'yatti: Anna, 2018, pp. 303-305.

\section{ДАННЫЕ ОБ АВТОРАХ}

Александрова Виктория Викторовна, доцент кафедры экологии, к.б.н. ФГБОУ ВО «Ниюневартовский государственный университет» ул. Ленина, 56, г. Нижневартовск, 628605, Российская Федерачия aleksandrovavv2006@yandex.ru

Иванов Вячеслав Борисович, доцент кафедры экологии, к.П.н. ФГБОУ ВО «Ниюневартовский государственный университет» ул. Ленина, 56, г. Нижневартовск, 628605, Российская Федераиия karatazh@mail.ru 
Войтова Виктория Александровна, ведущий инженер отдела химизации производственных процессов $A O$ «Самотлорнефтегаз - Роснефть ул. Ленина, 4, г. Нижневартовск, 628605, Российская Федераџия voitovava@mail.ru

DATA ABOUT THE AUTHORS

Aleksandrova Viktoria Vikorovna, Associate Professor

Nizhnevartovsk State University

56, Lenin St., Nizhnevartovsk, 628605, Russian Federation aleksandrovavv2006@yandex.ru ORCID: 0000-00034948-2912

Ivanov Vyacheslav Borisovich, Associate Professor

Nizhnevartovsk State University

56, Lenin St., Nizhnevartovsk, 628605, Russian Federation karatazh@mail.ru

ORCID: 0000-0001-6617-4634

Vojtova Viktoria Aleksandrovna, Lead Engineer of the Production Process Chemization Department Rosneft, Samotlorneftegaz JSC 4, Lenin St., Nizhnevartovsk, 628605, Russian Federation voitovava@mail.ru 